\title{
The Relationship between Periodontal Diseases and Plasma Level of Copper and Magnesium
}

\section{Aous Dannan* and Youssef Hanno}

Syrian Private University, Damascus, Syria

\begin{abstract}
Periodontitis is an immuno-inflammatory condition initiated by the dental plaque biofilm. Balanced levels of trace minerals like iron are essential to prevent progression of chronic conditions such as periodontitis. Their excess as well as deficiency is detrimental to periodontal health. The aim of the current study was to find out any possible relationship between copper and magnesium levels in the plasma and periodontal diseases.

The sample of the study included 29 patients seeking periodontal treatment. Full record of every patient was completed and the periodontal situation was determined clinically. Blood samples were collected from the patients and transferred to a medical laboratory for blood testing. The records of copper $(\mathrm{Cu})$ and magnesium $(\mathrm{Mg})$ in plasma were collected. T-test was used to compare the obtained values with the normal ones, and to compare the values obtained in paired samples. The differences were considered significant when $\mathrm{P}<0.05$.
\end{abstract}

The mean levels of copper in plasma were $148.88 \mathrm{mg} / \mathrm{dl}$ and $148.56 \mathrm{mg} / \mathrm{dl}$ for patients suffering acute gingivitis and chronic gingivitis respectively.

The results of T-test showed no significant differences between the records in both patients' groups. The mean scores of magnesium were $1.85 \mathrm{mg} / \mathrm{dl}$ and $2.03 \mathrm{mg} / \mathrm{dl}$ for patients suffering acute gingivitis and chronic gingivitis respectively and T-test showed a significant difference between the records. The mean scores of copper were 166.33 $\mathrm{mg} / \mathrm{dl}$ and $164.83 \mathrm{mg} / \mathrm{dl}$ for patients suffering chronic periodontitis and aggressive periodontitis respectively with no statistically significant difference between the records. The mean records of magnesium in plasma were $2.25 \mathrm{mg} / \mathrm{dl}$ and $2.48 \mathrm{mg} / \mathrm{dl}$ for patients suffering chronic periodontitis and aggressive periodontitis respectively and T-tests showed a significant difference between those records. The records of magnesium and the copper were significantly increased in all patients more than the normal values.

The results of the current study showed a remarkable increase of copper and magnesium plasma scores in patients suffering different types of periodontal diseases. More studies to explore the mechanism of magnesium increase in plasma due to periodontal disease are needed. Representing the records of magnesium and copper in plasma as indicators for the severity of periodontal disease might come under future research focus

Keywords: Periodontitis; Dental; Plaque; Minerals

\section{Introduction}

Periodontitis is an infection disease that affects the hard and soft tissues surrounding the teeth, and it is demonstrated as destruction in alveolar bone and connective tissue. It is a multifactorial disease in which many factors could contribute to its severity including diabetes mellitus, smoking, the host response, and the nutrition conditions [1].

Although periodontal diseases are highly connected to special kinds of pathogenic bacteria, most of gingival tissues could be damaged when host response is not sufficiently resistant against microorganisms, as well as due to the lack of balance between nutrition conditions and destructive factors [2].

Nutrition has a big effect on the inflammatory responses in the human body as well as on the cellular immunity. It also plays an important role in wound healing, and periodontitis is such a kind of wounds in which good circumstances of nutrition is necessary to complete their healing process.

The daily nutrition of human contains macronutrients and micronutrients. The need for micronutrients is measured by microgram or milligram, it contains, for example, vitamins and minerals. The daily need for some micronutrients like copper, iron, and zinc is about 100 microgram. Those elements have different functions and metabolic features, which considered necessary for the general health. They are also necessary for some enzymatic systems in the body like DNA, RNA, and alkaline phosphatase [3]. However, the critical mechanism in which micronutrients contribute to periodontal destruction is still unknown and hardly represented in clinical studies.

The aim of the current study was to find out any possible relationship between copper and magnesium scores in the plasma and periodontal diseases.

\section{Materials and Methods}

The sample of the study included 29 systemically-healthy patients (12 males and 17 females) who visited the dental clinics of the Faculty of Dentistry in the Syrian Private University in Damascus, and were seeking periodontal treatment due to several reasons. Oral consents were received from all patients to get their approval for being incorporated in the study. The aim of the study was explained to all patients and full record of every patient was completed including general information, and the periodontal situation was determined clinically through intra-

*Corresponding author: Aous Dannan, Dr med dent, Department of Periodontology, Faculty of Dentistry, Syrian Private University, Damascus, Syria, Tel: +963 11639 0210; E-mail: aousdannan@yahoo.com

Received Janaury 23, 2018; Accepted February 07, 2018; Published February 14,2018

Citation: Dannan A, Hanno Y (2018) The Relationship between Periodontal Diseases and Plasma Level of Copper and Magnesium. Dentistry 8: 471 doi:10.4172/2161-1122.1000471

Copyright: $\odot 2018$ Dannan A, et al. This is an open-access article distributed under the terms of the Creative Commons Attribution License, which permits unrestricted use, distribution, and reproduction in any medium, provided the original author and source are credited. 
oral examination and by means of $\mathrm{x}$-ray panoramic records. Acute gingivitis was considered available when patients suffered spontaneous gingival bleeding with swelled and light reddish appearance of the gingiva, while chronic gingivitis was considered available when the patients showed gingival bleeding on probing with swelled and dark reddish appearance of the gingiva. The diagnosis of periodontitis was done in the light of the age of patient, the familial history, the amount of dental plaque persisted, the amount of bone destruction, and the depth of periodontal pockets. The classification of the American Academy of Periodontology in 1999 [4] was appointed in order to distinguish both types of periodontitis assuming that chronic periodontitis was usually seen in adult patients with a considerate amount of dental plaque and probably with some local factors like smoking, irritating prosthetics, bad fillings, and bad oral hygiene. Aggressive periodontitis was usually related to younger patients with less amount of dental plaque, and, in many cases, was related to past familial history.

Blood samples $\left(2 \mathrm{~cm}^{3} /\right.$ Patient $)$ were collected from the patients (left or right arm with no preferences) and preserved in special tubes. Blood samples were transferred as soon as possible to a specialized medical laboratory for blood testing. The laboratory staffs were asked to measure the records of copper $(\mathrm{Cu})$ and magnesium $(\mathrm{Mg})$ in plasma. The blood samples were analysed by means of spectrometer device and the results for every patient were recorded on a special registration card that was, later on, attached to the clinical intraoral sheet of the patient. Statistical analysis software (SPSS IBM 21) was used to analyse the obtained data. T-test was used to compare the obtained values with the normal ones, and to compare the values obtained in paired samples. The differences were considered significant when $\mathrm{P}<0.05$

\section{Results}

The sample of the study included 29 patients who were suffering different kinds of periodontal diseases distributed as follows: Eight patients with acute gingivitis, 9 patients with chronic gingivitis, 6 patients with chronic periodontitis, 6 patients with aggressive periodontitis (Table 1).

When comparing the scores of copper and magnesium in plasma with the normal values, the following results were shown: First of all, it has to be mentioned that the normal values of magnesium in plasma range between $1.3 \mathrm{mg} / \mathrm{dl}$ and $2.1 \mathrm{mg} / \mathrm{dl}$, and the normal values of copper in males range between $70 \mathrm{mg} / \mathrm{dl}$ and $140 \mathrm{mg} / \mathrm{dl}$, and between $80 \mathrm{mg} /$ $\mathrm{dl}$ and $155 \mathrm{mg} / \mathrm{dl}$ in females (10). Therefore, and in order to facilitate the statistical analysis, we took the mean value of the normal range of magnesium which was $1.7 \mathrm{mg} / \mathrm{dl}$ and also the mean value of the normal range of copper in plasma for both male and female which was about $111.2 \mathrm{mg} / \mathrm{dl}$. We compared the scores of copper and magnesium obtained in the study with the normal values mentioned above.

Regarding the records of magnesium $(2.12 \mathrm{mg} / \mathrm{dl})$, the statistical analysis showed that those records were significantly increased in all patients more than the normal values $(\mathrm{P}<0.05)$ (Table 2$)$.

Regarding the records of copper in plasma $(155.8 \mathrm{mg} / \mathrm{dl})$, the statistical analysis showed that those records were significantly increased in all patients more than the normal values $(\mathrm{P}<0.05)$ (Table 3).

It was shown that the scores of copper in plasma for all patients ranged from $144 \mathrm{mg} / \mathrm{dl}$ to $172 \mathrm{mg} / \mathrm{dl}$ with a mean of $155.8 \pm 9.07$ (SD). The scores of magnesium in plasma for all patients ranged from $1.7 \mathrm{mg} /$ $\mathrm{dl}$ to $2.6 \mathrm{mg} / \mathrm{dl}$ with a mean of $2.12 \pm 0.23$ (SD). Table 4 demonstrates the scores of copper and magnesium as recorded for the patients.
The mean scores of copper in plasma were $148.88 \mathrm{mg} / \mathrm{dl}$ and 148.56 $\mathrm{mg} / \mathrm{dl}$ for patients suffering acute gingivitis and chronic gingivitis respectively. The results of T-test showed no statistically significant differences between the records in both patients' groups (i.e. between acute and chronic gingivitis) $(\mathrm{P}>0.05)$.

Regarding the scores of magnesium between both groups of patients who were suffering acute gingivitis and chronic gingivitis, it was shown that the mean scores of magnesium were $1.85 \mathrm{mg} / \mathrm{dl}$ and $2.03 \mathrm{mg} / \mathrm{dl}$ for patients suffering acute gingivitis and chronic gingivitis respectively. T-test showed a statistically significant difference between the records $(\mathrm{P}<0.05)$ (Tables 5 and 6$)$.

Regarding the scores of magnesium between both groups of patients who were suffering chronic periodontitis and aggressive periodontitis, it was shown that the mean scores of copper were $166.33 \mathrm{mg} / \mathrm{dl}$ and $164.83 \mathrm{mg} / \mathrm{dl}$ for patients suffering chronic periodontitis and aggressive periodontitis respectively. However, the results of T-test did not show any statistically significant difference between the records $(\mathrm{P}>0.05)$.

The mean records of magnesium in plasma were $2.25 \mathrm{mg} / \mathrm{dl}$ and

\begin{tabular}{|c|c|c|c|}
\hline \multicolumn{4}{|c|}{ Category of Periodontal Disease } \\
\hline \multirow{4}{*}{ Valid } & Acute Gingivitis & 8 & 27.5 \\
\cline { 2 - 4 } & Chronic Gingivitis & 9 & 31 \\
\cline { 2 - 4 } & Chronic Periodontitis & 6 & 20.6 \\
\cline { 2 - 4 } & Aggressive Periodontitis & 6 & 20.6 \\
\cline { 2 - 4 } & Total & 29 & 100.0 \\
\hline
\end{tabular}

Table 1: Distribution of patients according to the categories of periodontal diseases

\begin{tabular}{|c|c|c|c|}
\hline & $\mathbf{N}$ & Mean & Std. Deviation \\
\hline \multirow{4}{*}{ Mg Values (mg/dl) } & 29 & 2.120 & 0.2384 \\
\hline & \multicolumn{3}{|c|}{ Test Value $=1.7$ (Normal Value) } \\
\hline & \multicolumn{2}{|c|}{ Sig. (2-tailed) } & Significance \\
\hline & \multicolumn{2}{|c|}{0.000} & $\mathrm{~S}$ \\
\hline
\end{tabular}

Table 2: Results of T-test comparing the scores of magnesium extracted in the study with the normal value (S: significant).

\begin{tabular}{|c|c|c|c|}
\hline \multirow{2}{*}{ Cu Values } & N & Mean & Std. Deviation \\
\cline { 2 - 4 } & 29 & 155.83 & 9.079 \\
\cline { 2 - 3 } (mg/dl) & \multicolumn{2}{|c|}{ Test Value = 111.2 (Normal Value) } \\
\cline { 2 - 3 } & \multicolumn{2}{|c|}{ Sig. (2-tailed) } & Significance \\
\cline { 2 - 3 } & 0.000 & $\mathrm{~S}$ \\
\hline
\end{tabular}

Table 3: Results of T-test comparing the scores of copper extracted in the study with the normal value (S: significant).

\begin{tabular}{|l|c|c|c|c|c|}
\hline \multicolumn{7}{|c|}{ Descriptive Statistics } \\
\hline & N & Minimum & Maximum & Mean & Std. Deviation \\
\hline Cu Values (mg/dl) & 29 & 144 & 172 & 155.83 & 9.079 \\
\hline Mg Values (mg/dl) & 29 & 1.7 & 2.6 & 2.12 & 0.2384 \\
\hline
\end{tabular}

Table 4: Scores of copper and magnesium for all patients.

\begin{tabular}{|c|c|c|c|c|}
\hline & $\begin{array}{c}\text { Category of Periodontal } \\
\text { Disease }\end{array}$ & N & Mean & Std. Deviation \\
\hline $\begin{array}{c}\text { Cu Values } \\
\text { (mg/dl) }\end{array}$ & Acute Gingivitis & 8 & 148.88 & 2.357 \\
\hline Chronic Gingivitis & 9 & 148.56 & 2.651 \\
\hline $\begin{array}{c}\text { Mg Values } \\
\text { (mg/dl) }\end{array}$ & Acute Gingivitis & 8 & 1.85 & 0.0756 \\
\cline { 2 - 4 } & Chronic Gingivitis & 9 & 2.03 & 0.0500 \\
\hline
\end{tabular}

Table 5: Scores of copper and magnesium for patients suffering acute and chronic gingivitis. 


\begin{tabular}{|c|c|c|c|} 
& $\begin{array}{c}\text { Sig. (2-tailed) } \\
\text { (P Value) }\end{array}$ & $\begin{array}{c}\text { Mean Difference } \\
\text { (chronic periodontitis - } \\
\text { aggressive periodontitis) }\end{array}$ & Significance \\
\hline $\begin{array}{c}\text { Cu Values } \\
\text { (mg/dl) }\end{array}$ & 0.798 & 0.319 & NS \\
\hline $\begin{array}{c}\text { Mg Values } \\
\text { (mg/dl) }\end{array}$ & 0.000 & -0.1833 & $\mathrm{~S}$ \\
\hline
\end{tabular}

Table 6: Results of T-test comparing the scores of copper and magnesium for patients suffering acute and chronic gingivitis (S: significant, NS: not significant).

\begin{tabular}{|c|c|c|c|c|}
\hline & $\begin{array}{c}\text { Category of Periodontal } \\
\text { Disease }\end{array}$ & N & Mean & Std. Deviation \\
\hline $\begin{array}{c}\text { Cu Values } \\
\text { (mg/dl) }\end{array}$ & Chronic Periodontitis & 6 & 166.33 & 4.320 \\
\cline { 2 - 5 } & Aggressive Periodontitis & 6 & 164.83 & 5.879 \\
\hline $\begin{array}{c}\text { Mg Values } \\
\text { (mg/dl) }\end{array}$ & Chronic Periodontitis & 6 & 2.25 & 0.0548 \\
\hline & Aggressive Periodontitis & 6 & 2.48 & 0.0753 \\
\hline
\end{tabular}

Table 7: Scores of copper and magnesium for patients suffering aggressive and chronic periodontitis.

\begin{tabular}{|l|c|c|c|} 
& $\begin{array}{c}\text { Sig. (2-tailed) } \\
\text { (P Value) }\end{array}$ & $\begin{array}{c}\text { Mean Difference } \\
\text { (chronic periodontitis - } \\
\text { aggressive periodontitis) }\end{array}$ & Significance \\
\hline Cu Values (mg/dl) & 0.625 & 1.50 & NS \\
\hline Mg Values (mg/dl) & 0.000 & -0.23 & S \\
\hline
\end{tabular}

Table 8: Results of T-test comparing the scores of copper and magnesium for patients suffering aggressive and chronic periodontitis (S: significant, NS: not significant).

$2.48 \mathrm{mg} / \mathrm{dl}$ for patients suffering chronic periodontitis and aggressive periodontitis respectively. T-tests showed a statistically significant difference between those records $(\mathrm{P}<0.05)$, confirming that the records of magnesium were significantly higher in patients with aggressive periodontitis than those with chronic periodontitis (Tables 7 and 8).

\section{Discussion}

The results of the current study showed a remarkable increase in the scores of copper in plasma in the patients who were affected by periodontal diseases in general, and especially for those who were suffering aggressive periodontitis. These results were compatible with those previously published by Freeland et al. 1976, who found higher records of copper in plasma in patients affected by periodontal diseases.

Turnlund, et al. (1998) showed that the increase in copper scores in plasma could change the immunological function and the conditions of antioxidants [5].

Other studies showed that the higher records of copper in plasma could change the collagen metabolism, and it could also prepare a good environment for an inflammation to take place in the periodontal tissues [6].

On the other side, the process of inflammation in general could make an increase in the records of copper in plasma. For instance, Pekarek, et al. (1972) showed that copper in blood, which exists in the form of "Ceruoplasmin", could be released as a feedback signal initiated by some immunological mediators related to the white blood cells. However considering higher records of copper in plasma as a risk factor for periodontal disease is still a debate and needs more comprehensive studies [7]

Two different theories could be stated regarding the copper values in plasma. The first theory states that the higher copper values could be a direct result of periodontal disease, while the second theory states that the increase of those records affects the intensity of periodontitis.
However, due to the fact that the nutrition consumption of copper is not related to the values of copper in plasma, it could be stated that to higher increase of copper values in plasma in our study is a direct cause of periodontitis [8].

It has to be mentioned that some changes in collagen metabolism are also related to the increase of copper records in plasma in general, and, therefore, the activity of collagenase enzyme is closely related to the level of gingival inflammation due to the fact that collagenase plays an important role in the metabolic process in the periodontal tissues and it is probably related to the big loss of connective tissue occurs in periodontitis.

Similarly, it was previously shown that elevated levels of Iron $(\mathrm{Fe}) \mathrm{n}$ plasma showed a negative impact on periodontal health $[8,9]$.

More recently, Sundaram, et al. [10] conducted a study To find out the effect of nonsurgical periodontal therapy on serum zinc, magnesium, and copper concentration and glycemic status in type 2 diabetes with chronic periodontitis. They found that after nonsurgical periodontal management, there is an increase in the zinc and magnesium content and decrease in the copper content.

To our knowledge there is no studies in the literature which examined the increase or decrease of magnesium records in plasma in patients suffering periodontitis.

However the results of the current study regarding the mean values of magnesium were similar to those related to copper. The magnesium scores in patients suffering chronic periodontitis where less than those in patients suffering aggressive periodontitis, and this difference was statistically significant. The scores of magnesium were higher in all patients than the normal values in plasma for those who were suffering periodontal diseases in general. The mechanism of magnesium increase in plasma in patients with periodontal disease still needs more immunological, histological and biochemical studies.

The clinical importance of the current study comes through the idea of representing the records of magnesium and copper in plasma as indicators for the intensity of periodontal disease.

\section{Conclusion}

The results of the current study showed a remarkable increase of copper and magnesium plasma scores in patients suffering chronic and aggressive periodontitis and also in patients suffering chronic and acute gingivitis. We suggest the performance of more comprehensive studies to explore the exact mechanism of magnesium increase in plasma due to periodontal disease and also to find the relationship between periodontal diseases and the scores of copper in plasma.

\section{References}

1. Van Dyke TE, Dave S (2005) Risk factors for periodontitis. J Int Acad Periodontol 7: 3 .

2. Van Dyke TE, Lester MA, Shapira L (1993) The role of the host response in periodontal disease progression: implications for future treatment strategies. J Periodontol 64: 792-806

3. Nizel AE, Papas AS (1989) Nutrition in clinical dentistry

4. Armitage GC (1999) Development of a classification system for periodontal diseases and conditions. Ann Periodontol 4: 1-6.

5. Turnlund JR (1998) Human whole-body copper metabolism. Am J Clin Nutr. 67: $960-964$

6. Burch RE, Hahn HK, Sullivan JF (1975) Newer aspects of the roles of zinc manganese, and copper in human nutrition. Clin Chem 21: 501-520. 
Citation: Dannan A, Hanno Y (2018) The Relationship between Periodontal Diseases and Plasma Level of Copper and Magnesium. Dentistry 8: 471. doi:10.4172/2161-1122.1000471

7. Pekarek RS, Wannemacher Jr RW, Beisel WR (1972) The effect of leukocytic endogenous mediator (LEM) on the tissue distribution of zinc and iron. Proc Soc Exp Biol Med 140: 685-688.

8. Thomas B, Gautam A, Prasad BR, Kumari S (2013) Evaluation of micronutrient (zinc, copper and iron) levels in periodontitis patients with and without diabetes mellitus type 2: A biochemical study. Indian J Dent Res 24: 468.
9. Gaur S, Agnihotri R (2017) Trace mineral micronutrients and chronic periodontitis-a review. Biol Trace Elem Res 176: 225-238.

10. Sundaram G, Ramakrishnan T, Parthasarathy H, Moses J, Lalitha T (2017) Evaluation of micronutrient (Zinc, Magnesium, and Copper) levels in serum and glycemic status after nonsurgical periodontal therapy in type 2 diabetic patients with chronic periodontitis. Contemp Clin Dent 8: 26. 